NBER WORKING PAPER SERIES

\title{
THE CHANGING RELATIONSHIP BETWEEN AGGREGATE \\ PRICE AND OUTPUT: \\ THE BRITISH EXPERIENCE
}

\author{
Richard T. Froyen \\ Roger N. Waud
}

Working Paper No. 1134

\author{
NATIONAL BUREAU OF ECONOMIC RESEARCH \\ 1050 Massachusetts Avenue \\ Cambridge MA 02138
}

June 1983

The research reported here is part of the NBER's research program in Financial Markets and Monetary Economics. Any opinions expressed are those of the authors and not those of the National Bureau of Economic Research. 
The Changing Relationship Between Aggregate Price and Output: The British Experience

\title{
ABSTRACT
}

Over the past two and a half decades Great Britain has exhibited the most noticeable increase in inflation variability among the ten major noncommunist industrialized countries. In addition, there has been an apparent worsening in the output-inflation tradeoff. This paper attempts to identify and empirically assess possible causes of the deterioration in the British output-inflation tradeoff in the context of a new classical-type model. Supply-side shocks can cause an increase in the inflation rate and a decrease in real output, and it is estimated that such shocks interacted with inflation variability to reduce real output roughly 3.3 percent between the period 1957-1968 and the period 19691980. Also contributing to the deterioration in the output-inflation tradeoff, it is estimated that the decline in the natural rate of real output due to inflation variability (as hypothesized by Milton Friedman) amounted to about 2.3 to 2.5 percent between these two subperiods.

\author{
Richard T. Froyen \\ and \\ Roger N. Waud \\ Department of Economics \\ Gardner Hall 017A \\ University of North Carolina - \\ Chapel Hill \\ Chapel Hi1l, North Carolina 27514
}

(919) 966-5332 
Over the past two and a half decades Great Britain has exhibited the most noticeable increase in inflation variability among the ten major noncommunist industrialized countries. ${ }^{1}$ In addition, there has been an apparent worsening in the output-inflation tradeoff in Great Britain. The unusually high variability of the British inflation rate, together with the large supply-side shocks of the last decade, poses an interesting question. Namely, to what extent can the deterioration of the output-inflation tradeoff in the British economy be explained in terms of each of the following?

1) the effect of aggregate demand variability according to the new classical view of the output-inflation tradeoff, first specified by Robert Lucas (1972; 1973);

2) the effect of supply-side shocks, particularly energy price shocks;

3) the effect of inflation variability on the natural rate of real output, as hypothesized by Milton Friedman (1977).

This paper attempts to empirically assess this question within a framework which allows a separate and identifiable role for each of these three effects.

The first type of effect, according to the new classical view, arises because real output responds only to unanticipated changes in aggregate demand, and because that response is inversely related to the variability of inflation and aggregate demand. Hence, the apparent worsening of the output-inflation tradeoff could be explained by increased variability of inflation and aggregate demand.

The second type of effect, due to supply-side shocks such as the sudden increases in energy prices during the 1970s, could cause an increase in the inflation rate and a decrease in real output, other things equal. This effect might account for at least some of the apparent shift in the output-inflation tradeoff.

The third type of effect--Friedman's view (1977, pp. 464-468)--is allegedly due to the increased variability of the inflation rate causing a reduction in the allocative efficiency of the price system, which in turn causes a reduction in the natural rate of real output. This effect would give rise to a negative relationship between the inflation rate and real output because high inflation rates tend to be 
associated with greater inflation variability, again contributing to a deterioration in the output-inflation tradeoff.

In section I we construct a model which potentially allows each of the three effects to contribute in a separate, identifiable way to explaining the apparent deterioration in the output-inflation tradeoff. The model extends the Lucas-type model (as modified by Cukierman and Wachtel (1979)) to explicitly incorporate supply-side factors, such as energy prices. In addition, the model is modified to allow for a natural rate that varies for the kinds of reasons suggested by the Friedman view. The interpretation of the three effects within the context of the model is discussed in section II. Empirical specification and related issues are discussed in section.III. Estimates of the model for Great Britain for the years 1957-1980 are presented in section IV of the paper; the implications of these estimates are examined to assess the possible significance of each of the three effects for the observed shift in the output-inflation tradeoff in Great Britain. Our conclusions are presented in section $\mathrm{V}$.

\section{The Model}

The model of this study is an extension of the Lucas-type model (1973) as amended by Cukierman and Wachtel (1979). While their models explicitly capture the type-1 effect noted above, they do not allow for the type-2 and type-3 effects--respectively, the effects of supply-side shocks and the effects of inflation variability on the natural rate of output. The Lucas-type framework is extended to incorporate these effects in the following way.

First, like Lucas and others, we assume that the economy is made up of a large number of "scattered, competitive markets" (Lucas, 1973, p. 327). Then for each of these markets we derive output supply equations. These are based on derived factor demand equations for energy and labor as well as labor supply functions at the individual market level. Market-specific supply is a function of the marketspecific product price, the market-specific capital stock, and the expected general price level. It is assumed that the supply shocks in the model arise from changes 
in the price of the energy input used in the production process. Aggregate demand is assumed unit elastic ${ }^{2}$ with the demand side of the model specified following Cukierman and Wachtel (1979); expectations formation is characterized in a manner consistent with the way actual aggregate price is determined in the model. Finally, the derived aggregate output equation of the model is

(1) $y_{t}=g_{0}-\frac{g_{2} \theta}{1-g_{2} \theta}\left(\Delta x_{t}-\delta\right)+\frac{g_{3}}{1-g_{2} \theta} \mu_{t}+g_{3} \phi(t)+g_{4} k_{t}$

where $y_{t}$ is aggregate real output, $\Delta x_{t}$ is the change in nominal income or aggregate demand shock, $\delta$ is the mean of $\Delta x_{t}, \mu_{t}$ is the aggregate energy price disturbance, $\phi(t)$ is a function of time, and $k_{t}$ is the aggregate capital stock (all variables in logs). 3 The coefficients in (1) are functions of $\theta$ and the supply equation parameters (the $g^{\prime} s$ ). Thr parameter $\theta$ embodies the information structure of the model because it can be shown to be a function of the variances of economy-wide and market-specific shocks.

In deriving (1) we have made the following assumptions about expectations formation and the nature of economy-wide and market-specific shocks. Expectations in a market are conditioned by the current market-specific product price, the distributions of market specific and aggregate demand shocks, and the lagged values of aggregate demand. It is assumed that the market specific demand shocks are normally distributed with mean zero, and that the aggregate demand shock $\Delta x_{t}$ is normally distributed with mean $\delta$ and variance $\sigma_{x}^{2}$. As regards market specific and aggregate energy prices, $q_{t}(v)$ and $q_{t}$ respectively, it has been assumed that

$$
\begin{aligned}
& q_{t}(v)=q_{t}+n_{t}(v) \\
& q_{t}=p_{t}+\phi(t)+\mu_{t}
\end{aligned}
$$

where $\eta_{t}(v)$ is the market-specific energy price disturbance, $p_{t}$ is the aggregate output price, $\phi(t)$ is a time trend in the relative price of energy, and $\mu_{t}$ is the aggregate energy price disturbance, and where

$$
\begin{aligned}
& n_{t}(v) \sim N\left(0, \sigma_{n}^{2}\right) \text { for all v } \\
& \mu_{t} \sim N\left(0, \sigma_{\mu}^{2}\right)
\end{aligned}
$$

and $n_{t}(v)$ and $\mu_{t}$ are independently distributed and serially uncorrelated. 4 


\section{Interpretation of the Three Effects Within the Model}

We will now explain the manner in which the three effects described above are incorporated in the model.

It is important for the type 1 and 2 effects that the information parameter $\theta$ appears in the coefficients in (1) which characterize the real output response to aggregate demand and supply shocks, $\Delta x_{t}$ and $\mu_{t}$ respectively. In particular, since $\theta$ is a function of the variances of economy-wide and market-specific shocks, the coefficients containing $\theta$ will also depend on these market-specific and aggregate variances. Moreover, it can be shown that $\theta$ is an increasing function of the variances of market-specific supply and demand shocks, and a decreasing function of the variances of the aggregate suppl: and demand shocks. 5

II. 1 The Type 1 Effect

The type 1 effect, the effect of aggregate demand variability, enters through the coefficient on $\left(\Delta x_{t}-\delta\right)$ in (1). Examination of this coefficient indicates that real output response to aggregate demand shocks is a declining function of the variability of the aggregate demand shock and an increasing function of the variability of market-specific demand shocks, a result analogous to that of previous Lucas-type models. However, our model also includes supply shocks, and inspection of the coefficient on $\left(\Delta x_{t}-\delta\right)$ in (1) reveals that the real output response to an aggregate demand shock is a declining function of the variability of aggregate supply shocks and an increasing function of the variability of market-specific supply shocks. Hence in our model the type 1 effect is augmented by the fact that the real output response to the aggregate demand shock, $\Delta \mathrm{x}_{\mathrm{t}}$ is a function of the variability of both demand and supply-side shocks. If the variability of the aggregate demand and/or the aggregate supply shocks Increases, then the coefficient on $\left(\Delta x_{t}-\delta\right)$ becomes smaller and there is a deterioration in the output-inflation tradeoff. That is, for a given size aggregate demand shock, $\Delta \mathrm{x}_{t}$ (the change in nominal income), the resulting increase in the price level is larger relative to the increase in real output. 
II.2 The Type 2 Effect: Supply-Side Shocks

The type 2 effect is incorporated into our model through the direct effect of the aggregate supply shock $\mu_{t}$ on aggregate real output and the price level, as indicated by the presence of $\mu_{t}$ in equation (1). For example, holding all other independent variables in (1) constant, a positive shock $\mu_{t}$ in the energy price will cause real output $y_{t}$ to decline (since $g_{3} /\left(1-g_{2} \theta\right)$ in (1) is negative) and the price level to rise (given the nominal income level $x_{t}=\Delta x_{t}+x_{t-1}$ ). Such shocks would certainly contribute to an apparent deterioration in the output-inflation tradeoff.

Just as the variability of demand and supply shocks affect the size of the coefficient on $\left(\Delta x_{t}-\delta\right)$ in (1), their variability also affects the size of the coefficient on $\mu_{t}$, and hence the size of the output response to $\mu_{t} \cdot$ Recalling the way in which this variability affects the size of $\theta$, inspection of $\mu_{t}$ 's coefficient $\left(E_{3} /\left[1-g_{2} \theta\right]\right)$ shows that the output response is an increasing function of the variability of both the aggregate demand and aggregate supply shocks, and a decreasing function of the variability of market-specific demand and suppiy shocks. The relationships between output responses to aggregate demand ard supply shocks and the variability of aggregate and marketspecific shocks can be given an economic interpretation in terms of aggregate demand and supply curves in aggregate price and output space. Increases in the variability of aggregate demand or supply shocks cause the aggregate supply curve to become more steeply sloped. Hence a given aggregate demand shock, represented by a horizontal shift in the aggregate demand curve along the aggregate supply curve, will cause output to change less. On the other hand, a given aggregate supply shock, represented by a horizontal shift in the aggregate supply curve along the aggregate demand curve, will cause output to change more. 


\section{II.3 The Type 3 Effect: Inflation Variability and the Natural Rate}

Friedman (1977) has suggested that because of rigidities due to institutional and political arrangements, high variability of inflation--whether caused by variability of aggregate demand or supply--causes a loss of efficiency in the price system and a likely rise in unemployment. Friedman would expect this positive relationship between inflation variability and unemployment to show up as a positive association between the level of the inflation rate and the level of the unemployment rate, because bigh inflation rates and greater inflation variability have tended to go together. Since a rise in the unemployment rate typically implies a decline in real output, we would observe a deterioration in the output-inflation tradeoff. 6 While Friedman suggests that the positive (negative) relationship between inflation variability and unemployment (output) "seems plausible," he does not argue that such a relationship follows as a necessary implication of a theory; ${ }^{7}$ Friedman's view is an empirical proposition.

To incorporate the Friedman view or type 3 effect, the effect of inflation variability on the natural rate of output, we follow Lucas (1973) and divide the factors which influence output in equation (1) into those affecting the natural rate $\left(y_{n, t}\right)$, and those that cause cyclical fluctuations $\left(y_{c, t}\right)$ around the natural rate:

(2) $y_{t}=y_{n, t}+y_{c, t}$

(3) $y_{n, t}=g_{0}+g_{3} \phi(t)+g_{4} K_{t}$

(4) $y_{c, t}=\frac{-g_{2} \theta}{1-g_{2} \theta}\left(\Delta x_{t}-\delta\right)+\frac{g_{3}}{1-g_{2} \theta} \mu_{t}$.

We get Lucas's specification of the natural rate if in (3) it is assumed that $\phi(t)$ and $\mathrm{K}_{\mathrm{t}}$ follow a linear trend. ${ }^{8}$ Friedman's view suggests that, in addition, the natural rate of output depends on the variability of inflation. It can be shown that in our model the variability of inflation will depend on the variability of aggregate supply and demand. 9

To capture the type 3 effect the Friedman view suggests that the natural rate be specified 
(5) $y_{n, t}=a+b t+\beta_{1}\left(\begin{array}{cc}\sigma^{2} & -\bar{\sigma}^{2} \\ \Delta p, t & \Delta p\end{array}\right) \quad \beta_{1}<0$

where $\sigma_{\Delta \mathrm{p}, t}^{2}$ is the variance of the inflation rate at $t$ and $\sigma_{\Delta \mathrm{p}}^{-2}$ is the mean of that variance. 10 Any increase in the variability of the inflation rate, as measured by $\sigma_{\Delta p, t}^{2}$, causes a decline in the natural rate of output--the type 3 effect. (The empirical proxy for $\sigma_{\Delta p, t}^{2}$ is discussed below.) Hence, for given values of all the other independent variables in (4) and (5), particularly the change in nominal income $\Delta x_{t}$, real output $y_{t}$ in (2) will fall and the price level must rise thus contributing to a deterioration in the output-inflation tradeoff.

\section{Empirical Specification of the Model}

The output equation implied by our model is equation (1) modified to specify the natural rate as given by equation (5).

\section{III.1 Measuring Inflation Variability}

If inflation variability tends to change over time, we need to construct a time-varying measure of inflation variability--a proxy for $\sigma_{\Delta \mathrm{p}, t}^{2}$. The variability of the variance of the distribution of the inflation rate is difficult to measure because we observe only one outcome from the distribution of the inflation rate at each point in time, and this alone is not enough to construct an estimate of $\sigma_{\Delta p, t}^{2}$ at each point in time. As a proxy for $\sigma_{\Delta p, t}^{2}$ we construct a moving variance of actual changes in the inflation rate, $\hat{\sigma}_{\Delta \mathrm{p}, \mathrm{t}}^{2}$

It is unavoidedly an arbitrary choice as to how many periods should be used to construct $\hat{\sigma}_{\Delta \mathrm{p}, \mathrm{t}}^{2}$. We compute $\hat{\sigma}_{\Delta \mathrm{p}, \mathrm{t}}^{2}$ at each point in time using observations from the past 8 quarters, exclusive of the current quarter. The moving variance proxy at time $t$ is computed from data in past periods so that it will not contain information unavailable to agents at time t. ${ }^{11}$

III.2 Detrending Aggregate Demand Growth

Examination of the data for the change in the $\log$ of nominal income, $\Delta \mathrm{x}$, over the sample period 1957-80 suggested that $\Delta \mathrm{x}$ contained a statistically significant upward trend, instead of having a constant mean $\delta$. 
Hence we measured the aggregate demand shock $\Delta x$ as the detrended change in nominal income. It can be shown that the trend growth in $\Delta x$ has no effect on output in our model because such growth is anticipated by economic agents.

\section{III.3 Adjustment Lag}

Following Lucas (1973), we assume that due to adjustment lags there is some persistence to movement in output. We represent this persistence by including a lagged value of the dependent variable as an independent variable in the output equation. Lucas (1975) and Sargent (1977) have developed rationales for such persistence.

\section{III.4 Specification for Estimation}

Modifying ( 1 ) by the natural rate specification (5), the detrended aggregate demand shock $\Delta x_{t}$, and the addition of the lagged dependent variable, our model characterizes the behavior of detrended real output $y_{t}$ as (6) $y_{t}=\beta_{0}+\beta_{1} \hat{\sigma}_{\Delta p, t}^{2}-\frac{g_{2} \theta}{1-g_{2} \theta} \Delta x_{t}+\frac{g_{3} \theta}{1-g_{2} \theta} \mu_{t}+\lambda y_{t-1}$ where $\beta_{0}=-\beta_{1} \bar{\sigma}_{\Delta \mathrm{p}}^{2}$. Deviation of output from trend, the dependent variable, has a slightly different interpretation here than in the usual Lucas-type model where the deviation of output from trend is the cyclical component of output. In (6) output may deviate from trend both because of cyclical factors $\left(\Delta x_{t}\right.$ and $\left.\mu_{t}\right)$ and because of the effect of inflation variability on the natural rate of output. 12

In order to allow for the existence of type 1 and type 2 effects, in particular variation in the coefficients on $\Delta x_{t}$ (a type 1 effect) and $\mu_{t}$ (a type 2 effect), we need to implement an empirical specification which captures the way such effects occur in our model. As already discussed, the coefficierts on $\Delta x_{t}$ and $\mu_{t}$ are functions of the variances of both aggregate and market specific demand and supply shocks; the coefficient on $\Delta x_{t}$ is a decreasing function of the variance of aggregate demand, $\sigma_{x}^{2}$, and/or supply, $\sigma_{\mu}^{2}$, while the coefficient on $\mu_{t}$ is an increasing function of these variances. Moreover, the 
variance of the inflation rate is an increasing function of $\sigma_{x}^{2}$ and $\sigma_{\mu}^{2} .13$ Therefore the coefficient on $\Delta x_{t}$ is a decreasing function and the coefficient on $\mu_{t}$ an increasing function of the variance of the inflation rate.

\section{III.4.a Inflation Rate Variability and Type 1 and 2 Effects}

If the variances of aggregate demand and supply are changing over time, then so is the variance of the inflation rate, and, in turn, the coefficients on $\Delta x_{t}$ and $\mu_{t}$. Hence to capture type $I$ and 2 effects we allow the coefficients on both $\Delta x_{t}$ and $\mu_{t}$ to depend explicitly on our estimated measure of inflation variability, the moving variance of the inflation rate $\theta_{\Delta p, t}^{2}$. Letting $\beta_{\Delta x, t}$ and $\beta_{\mu, t}$ be the coefficients on $\Delta x_{t}$ and $\mu_{t}$ respectively, these coefficients are assumed to be functions of the following form: ${ }^{14^{-}}$

$$
\beta_{\Delta x, t}=\alpha_{10}+\alpha_{11} \theta_{\Delta p, t}^{2}
$$

$$
\beta_{\mu, t}=\alpha_{20}+\alpha_{2 l} \theta_{\Delta p, t}^{2}
$$

where $\alpha_{11}<0<\alpha_{2 I}$. With these substitutions, equation (6) now becomes

$$
\begin{aligned}
y_{t}= & \beta_{0}+\beta_{1} \theta_{\Delta p, t}^{2}-\left(\alpha_{10}+\alpha_{11} \hat{\sigma}_{\Delta p, t}^{2}\right) \Delta x_{t} \\
& +\left(\alpha_{20}+\alpha_{21} \theta_{\Delta p, t}^{2}\right) \mu_{t}+\lambda y_{t-1}
\end{aligned}
$$

or consolidating terms

$$
\begin{gathered}
y_{t}=\beta_{0}+\beta_{1} \theta_{\Delta p, t}^{2}-\alpha_{10} \Delta x_{t}-\alpha_{11} \theta_{\Delta p, t}^{2} x_{t} \\
+\alpha_{20} \mu_{t}+\alpha_{2 I} \theta_{\Delta p, t}^{2} \mu_{t}+\lambda y_{t-I}
\end{gathered}
$$

The two interaction terms between $\sigma_{\Delta p, t}^{2}$ and $\Delta x_{t}$ and $\mu_{t}$ measure the degree to which the coefficients on $\Delta x_{t}$ and $\mu_{t}\left(\beta_{\Delta x, t}\right.$ and $\beta_{\mu, t}$ respectively) vary as a consequence of changing inflation variability, as measured by the moving variance proxy $\sigma_{\Delta p, t}^{2}$. Examination of the signs and significance of the estimated 
coefficients on these interaction terms, $\alpha_{11}$ and $\alpha_{21}$, will indicate whether or not $\beta_{\Delta x, t}$ and $\beta_{\mu, t}$ vary systematically in a manner consistent with the existence of type 1 and 2 effects, respectively. Regarding the measurement of $\hat{\sigma}_{\Delta p}^{2}, t$, while Friedman's (1977) analysis and the new classical view, as expressed by Lucas (1973) for example, focus an inflation variability, other research has concentrated on inflation uncertainty [Evans (1978), Levi and Makin (1980)]. To test for the difference this distinction might make we detrended the inflation rate to remove the predictable trend part of the rate, and then constructed $\hat{\sigma}_{\Delta p, t}^{2}$ in the same manner already described. Use of the measure using the detrended inflation rate made no significant difference in our results what-so-ever. It is the results using the detrended inflation rate which are reported in Table 1.

Since the variance of the inflation rate is a function of the variances of aggregate demand and supply in our model, and since these variances $\left(\sigma_{x}^{2}\right.$ and $\sigma_{\mu}^{2}$ ) appear explicitly through $\theta$ in the coefficients on $\Delta x_{t}$ and $\mu_{t}$, it is also of interest to consider a specification which allows an identification of the separate contributions to a type 1, 2 or 3 effect due to changing aggregate demand variability on the one hand, or changing aggregate supply variability on the other. Analogous to equations (7) and (8), this can be done by specifying the natural rate and the coefficients on $\Delta x_{t}$ and $\mu_{t}$ in our estimating equation to depend explicitly on estimated time moving variances of aggregate demand and supply, $\hat{\sigma}_{x, t}^{2}$ and $\hat{\sigma}_{\mu ; t}^{2}$ respectively. (We construct these proxies in exactly the same way that the proxy $\hat{\sigma}_{\Delta \mathrm{p}, \mathrm{t}}^{2}$ is constructed, as described previously.)

\section{III.4.b Autocorrelation of the Supply Shock}

Examination of the data suggested the existence of first order autocorrelation in the supply shock $\mu$, whether measured by the energy price or the import price shock. Hence the aggregate supply shock should be specified

(9) $\mu_{t}=\xi \mu_{t-1}+\varepsilon_{t} \quad 1>\xi>0$.

Given this modification, the cyclical component of output becomes ${ }^{15}$ 
(4') $y_{c, t}=\frac{g_{2} \theta}{1-g_{2} \theta} \Delta x_{t}+g_{3} \xi \mu_{t-1}+\frac{g_{3}}{1-g_{2} \theta} \ddot{\varepsilon}_{t}$.

Unlike demand-side shocks, equation (4') implies that both the anticipated and the unanticipated components of a supply shock will affect real output.

It is readily apparent that the terms involving $\mu_{t-1}$ and $\varepsilon_{t}$ in (4') can be rewritten, using (9), so that they are replaced by tne terms

(10) $\frac{g_{3}}{\left(1-g_{2} \theta\right)} \mu_{t}-\frac{g_{3} g_{2} \theta \xi}{\left(1-g_{2} \theta\right)} \mu_{t-1}$.

It is econometrically easier to take account of the serial correlation in $\mu_{t}$ using (10) in $\left(4^{\prime}\right)$ because (10) does not require that we generate estimates of the disturbance term $\varepsilon_{t}$. Given that $g_{1}, g_{4}, \xi, \theta>0$ and $g_{2}, g_{3}<0$, the signs on the estimated coefficients on $\mu_{t}$ and $\mu_{t-1}$ should be negative.

\section{Mode1 Estimates}

The data used in this study are for the period 1957:I to 1980:IV. The actual sample period for estimation of (6) is 1959:II-1980:IV, because one quarter is lost in first differencing nominal income $(\Delta x)$ and eight quarters are used to create the proxy for the moving variance of the inflation rate. Two different measures of the supply shock $\mu_{t}$ were used: a measure of the price of energy, and a measure of the price of imports. ${ }^{16}$

\section{IV.1 Estimates Allowing for Type 2 and 3 Effects}

If we assume that the variability of inflation changes over time, so that $\hat{\sigma}_{\Delta \mathrm{p}, \mathrm{t}}^{2} \neq \bar{\sigma}_{\Delta \mathrm{p}}^{2}$, then we allow for a type 2 and a type 3 effect when we estimate the specification given by (6). That is, we allow for the effect of inflation variability on the natural rate of output, the type 3 effect, as well as the type 2 effect caused by the direct effect on real output of the aggregate supply shock $\mu_{t}$.

Lines 1 and 3 of Table 1 give the estimates of (6). Indeed, the estimates of $\beta_{0}$ (the constant) are significant and positive, and the estimates of $\beta_{1}$ are significant and negative, consistent with the a priori specification. All coefficient estimates are significant and of the expected sign in line 3, where the import-price measure 
is used for $\mu_{t}$. In line 1 , where the energy price measure is used for $\mu_{t}$, all coefficient estimates have the expected sign, but the coefficient on $\mu_{t}$ is not significant. Thus the estimates suggest the existence of a significant type 3 effect, using either measure of the supply shock $\mu_{t}$, and the existence of a type 2 effect when the import price measure is used. ${ }^{17}$

\section{IV.2 Estimates Allowing for Type 1,2, and 3 Effects}

To 2llow for the existence of all three effects at once, we estimate the specification of our model given by equation (8). These estimates are reported in Table 1, lines 2 and 4 .

When the energy price measure of the supply shock is used, line 2, the interaction term $\hat{\sigma}_{\Delta p, t}^{2} \Delta x_{t}$ is not significant, suggesting the lack of a type 1 effect, though demand side shocks $\Delta \mathrm{x}_{t}$ do have significant impacts on real output $\mathrm{y}_{t}$. When the import price measure is used, line 4, the results are very similar--demand side shocks appear significant, but the interaction term $\sigma_{\Delta p, t}^{2} \Delta x_{t}$ does not.

On the basis of the estimates in line 2, using the energy price measure of the supply shock, there is no evidence of a significant type 2 effect due to the direct effect of $\mu_{t}$ on $y_{t}$. Given the apparent insignificance of the interaction term $\hat{\sigma}_{\Delta \mathrm{p}, t}^{2}{ }_{t}$, there is also no evidence of a type 2 effect arising from a change in the size of the coefficient on $\mu_{t}$. The estimates using the import price measure of the supply shock, line 4, te11 a somewhat different story, however, because there the interaction term $\hat{\sigma}_{\Delta \mathrm{p}, t^{\mu}}^{2}$ is significant, though the direct effect of the supply shock is not. Hence the estimates of line 4 do suggest the existence of a type 2 effect because the coefficient on $\mu_{t}$ has increased.

The estimates in both lines 2 and 4 strongly suggest the existence of a type 3 effect. Indeed, the estimates of the coefficient on $\hat{\sigma}_{\Delta p, t}^{2}$ are very similar in both size and significance to those in lines 1 and 3 .

When we specified the natural rate and the coefficients on $\Delta x_{t}$ and $\mu_{t}$ to depend explicitly on time moving variances of aggregate demand and supply, $\hat{\sigma}_{x, t}^{2}$ and $\hat{\sigma}_{\mu, t}^{2}$ 
respectively, the estimated coefficient on the lagged dependent variable $y_{t-1}$ was implausibly high. In fact, for several of these specifications the point estimate of this coefficient was greater than one, violating the a priori specification of the adjustment $\mathrm{lag}$ in the model and raising doubts about the reliability of the other estimated coefficients in these specifications. ${ }^{18}$

Finally, when we allowed for the existence of serial correlation in the supply shock by using the specification (10) in our estimating equation, the coefficient on $\mu_{t-1}$ was significant with the expected sign while the coefficient on $\mu_{t}$ was not significant. The estimated coefficients on the other independent variables did not differ significantly from those in Table 1.

\section{IV.3 Specification Tests}

Regression specification error tests were performed in order to see if the estimated equations reported in Table 1 were misspecified due to omitted variables, incorrect functional form, or correlation between the explanatory variables and the disturbance term; the last possibility is of particular concern because of the presumed exogeneity of $\Delta \mathrm{x}_{t}$ and $\mu_{t}$. The procedure used to test for the existence of these problems was first suggested by Ramsey (1969) and subsequently examined by use of Monte Carlo experiments by Thursby and Schmidt (1977). Thursby and Schmidt examined several different ways of implementing Ramsey's procedure and concluded that the test which seemed generally best was one based on the inclusion in the regression of higher ordered powers of the explanatory variables. An F-test is used to see if the inclusion of these additional variables suggests the existence of misspecification due to omitted variables, incorrect functional form, or correlation between the explanatory variables and the disturbance term.

Such tests were performed for the estimated equations reported in Table 1 by adding second and third order powers of $\Delta x_{t}$ and $\mu_{t}$ to the regressions. The F-statistics for these tests are reported in the last column of Table 1. The only F-statistic significant at the 5 percent level was for the specification using the import price measure of the supply shock, omitting the interaction terms which allow for the type 1 effect, line 3 . When the interaction terms are added to give the specification reported in line 4 the 
F-statistic is no longer significant. These results are consistent with our finding of a significant interaction effect for $\partial_{\Delta p, t}^{2}{ }_{t}$ in line 4; the omission of this term in the regression of line 3 appears to be the reason why that regression is misspecified according to the F-statistic. Similarly, the absence of significant interaction effects in line 2 is consistent with the finding that the specification omitting these effects in line 1 is appropriate according to the F-statistic.

\section{IV.4 Quantitative Significance of Estimates}

We noted at the outset that Great Britain has exhibited the most noticeable increase in inflation variability among the ten major noncommunist industrialized countries during the period from the latter half of the $1950^{\prime}$ 's through 1980 . The variance of the inflation rate in Great Britain during the subperiod 1969I-1980IV was roughly two and a half times as large as during the subperiod 1957II-1968IV. Against this background it is of interest to consider the quantitative implications of our estimates in Table 1.

Consider first the estimates using the energy price measure of the supply shock, lines 1 and 2 of Table 1 , which strongly suggest the existence of a type 3 effect. We focus on the estimates of line 1 since the estimates of line 2 suggest that the interaction terms, $\varepsilon_{\Delta \mathrm{p}, \mathrm{t}}^{2} \Delta \mathrm{x}_{\mathrm{t}}$ and $\theta_{\Delta \mathrm{p}, \mathrm{t}}^{2} \mu_{\mathrm{t}}$, were not significant. Some idea of the quantitative significance of the type 3 effect is obtained by considering the impact of the increase in the size of the average value of the moving variance proxy $\partial_{\Delta p, t}^{2}$ between the first subperiod, 1957II-1968IV, and the second subperiod, 1969I-1980IV. ${ }^{19}$ This increase multiplied by the coefficient estimate of $\beta_{1}$ (from equation 8 or 5 ), the coefficient on $\sigma_{\Delta \mathrm{p}, \mathrm{t}}^{2}$ equal -60.5116 in Table 1 , suggests that increased inflation variability operating via the type 3 effect caused about a 2.5 percent reduction in the natural rate of real output $y_{n, t}$, and hence the actual level of real output $y_{t}$ (from equation 2), ceteris paribus. 20

Consider the estimates using the import price measure of the supply shock, in particular line 4 of Table 1 . These estimates suggest that inflation variability gave rise to both a type 3 effect and a type 2 effect, the latter due to the changing size of the coefficient on the supply shock $\mu_{t}$ as indicated by the significant estimate of 
$\alpha_{21}$ (equation 8 ), the coefficient on the interaction term $\hat{\sigma}_{\Delta \mathrm{p}, t}^{2} \mu_{t}$. The combined effect of inflation variability, due to both the type 2 and type 3 effects, can be calculated in a manner analogous to that used for the case of the energy price measure of the supply shock. This is done by using the coefficient estimates on the terms $\hat{\sigma}_{\Delta \mathrm{p}, \mathrm{t}}^{2}$ and $\hat{\sigma}_{\Delta \mathrm{p}, \mathrm{t}}^{2}{ }_{\mathrm{t}}$, from line 4 of Table 1 , in conjunction with the increase in the average values of $\hat{\sigma}_{\Delta \mathrm{p}, \mathrm{t}}^{2}$ and $\hat{\sigma}_{\Delta \mathrm{p}, \mathrm{t}}^{2}{ }_{\mathrm{t}}$ between the two subperiods, 1957II-1968IV and 1969I-1980IV. 21 The calcitation suggests that increased inflation variability operating via both the type 2 and 3 effects caused about a 5.5 percent reduction in the level of real output $\mathrm{y}_{\mathrm{t}}$ (from equation 2), ceteris paribus. ${ }^{22}$ The amount of this change due to the type 2 effect, the interaction of inflation variability with the supply shock, is roughly 3.3 percent, while the remaining 2.2 percent is due to the type 3 effect.

Both of the above calculations give the decline in the level of real output between the earlier and later subperiods for a given level of nominal income. These calculations, therefore, imply commensurate increases the average price level betwen the two periods, again ceteris paribus, due to type 3 , or type 2 and type 3 effects.

\section{Conclusions}

At the outset of this paper it was noted that over the period from 1957 to 1980 there appears to have been a deterioration in the output-inflation tradeoff in Great Britain. To what extent do our model estimates indicate that this deterioration may be explained in terms of the type 1,2 , and 3 effects?

Aggregate demand shocks $\Delta x_{t}$ were always found to have a significant effect on real output with the expected positive sign. However, we found no evidence that the coefficient on $\Delta x_{t}$ changed significantly in the manner suggested by the existence of a type 1 effect. Our results do provide some evidence that a type 2 effect played a role. In particular, that evidence suggests that the type 2 effect took the form of an increase in the absolute size of the coefficient on the supply shock $\mu_{t}$, brought about by an increase in the variability of the inflation rate, as proxied by our measure $\hat{\sigma}_{\Delta p, t}^{2}$. The type 3 effect appears to play a significant role in explaining the deterioration in the output-inflation 
tradeoff. The role of the changing variability of the inflation rate (proxied by $\hat{\theta}_{\Delta p, t}^{2}$ ), given by the natural rate specification in our model, was always significant with a negative sign. 


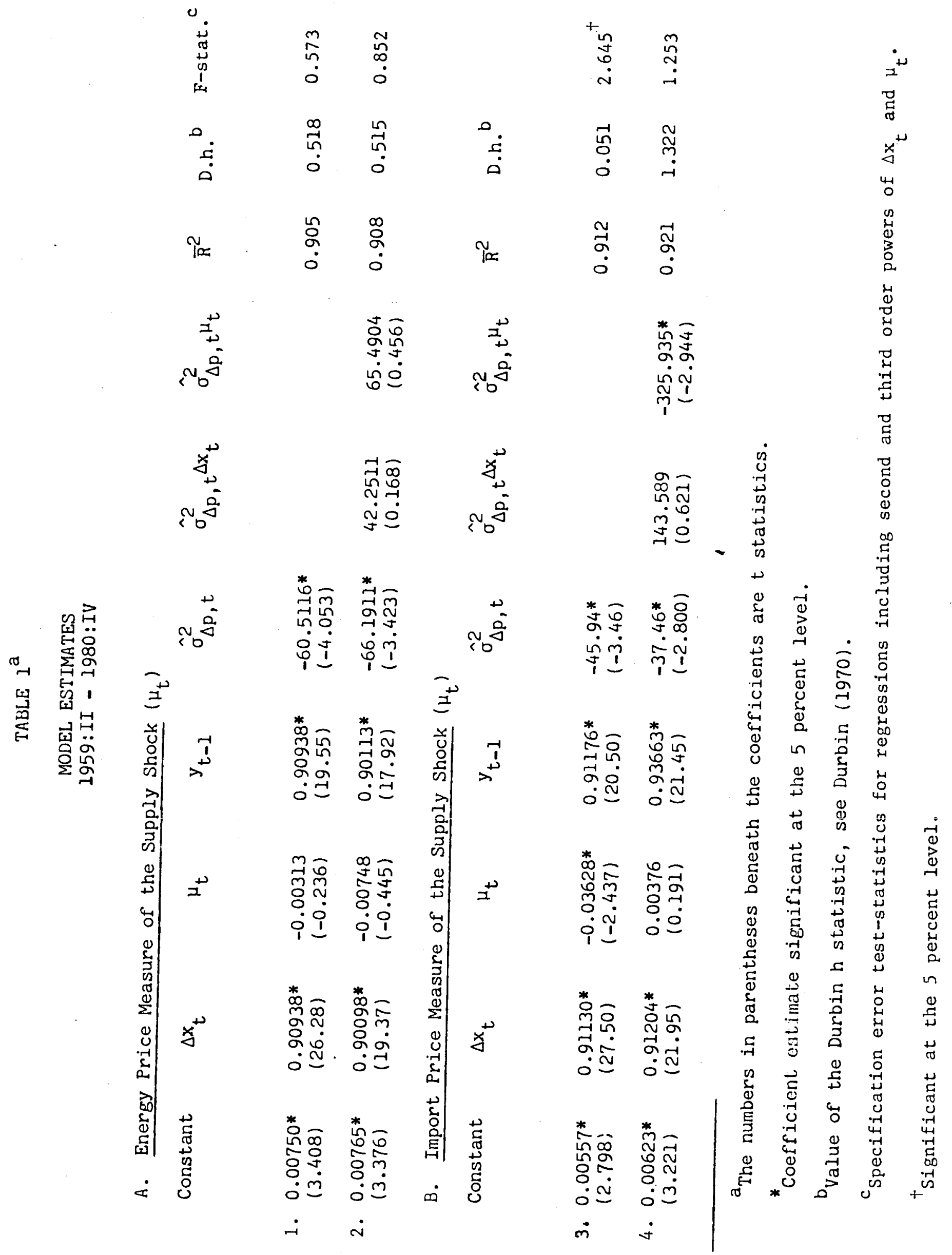




\section{FOOTNOTES}

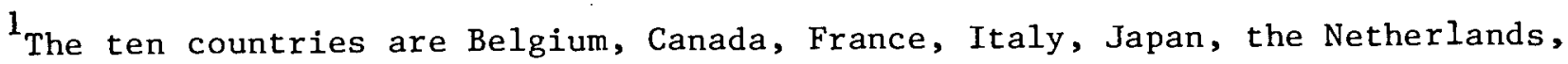
Switzerland, Great Britain, the United States, and West Germany.

${ }^{2}$ We will examine this assumption further below. This assumption considerably simplifies the analysis since with it no detailed specification of the elements of aggregate demand is required. Nelson's (1979), (1981) estimates provide support for such a recursive structure between nominal income and real output in the United States. Alberro (1981) tested the Lucas specification of aggregate demand for a wide sample of countries including the U.K. and found little evidence to refute that specification. (See also Froyen and Waud [1980, p. 420]).

${ }^{3}$ An appendix describing the complete derivation of (1) is available from the authors on request.

${ }^{4}$ Below we will examine the case where the aggregate energy price shock is serially correlated. Also, note that the specification of the energy price presumes that the aggregate price of energy is perfectly indexed to the aggregate domestic price level. Blinder (1981) considers the case where energy prices are imperfectly indexed. In that case, the monetary (or other policy) authority could potentially manipulate the relative price of energy by aggregate demand policy, a possibility not allowed for here. The model here could be modified to allow the aggregate energy price to be indexed to the expected rather than the actual. aggregate domestic price level without changing the generic form of the income equation estimated below.

${ }^{5}$ This is shown in the appendix cited in footnote 3.

${ }^{6}$ Evans (1978) points out that Keynes (1924) also posited a negative relationship between instability of the aggregate price level and the level of output. Okun (1981) recently argued, along somewhat different lines, that increased variability of aggregate demand would both steepen the Phillips curve and cause the curve to shift upwards, increasing the "inflation rate associated with the cycle average unemployment rate."

7 Evans (1978) has shown that within a labor market model where both the supply and demand for labor depend on the degree of uncertainty about the aggregate price level, employment may either increase or decrease in response to an increase in uncertainty. The ambiguity stems from the uncertain response of labor supply to an increase in aggregate price uncertainty. A recent paper by Azariadis (1981) demonstrates the ambiguity of the relationship between price level uncertainty and the natural rate of output within a general equilibrium model. Evans (1978), Levi and Makin (1980), and Mullineaux (1980) provide empirical evidence for the United States supporting the view that increased aggregate price uncertainty depresses the natural rate of employment or output. As Levi and Makin (1980, p. 1023) note, the relationship. between employment and inflation uncertainty is somewhat different from the relationship between inflation variability and output or employment suggested by Friedman. Friedman's notion would seem broader than those investigated by Evans, Levi and Makin, or Mullineaux in that increased uncertainty is only one channel by which increased inflation variability might affect output or employment. 
8 Note that within the overall framework of our model the systematic or time trend part of the energy price will show up in the natural rate $y_{n, t}$ via (3).

${ }^{9}$ This is shown in the appendix cited in footnote 3 . Within our model, since the lagged value of the price level is given, the varlance of the inflation rate can be shown to equal the variance of the aggregate price level. Within the model, the variance of the aggregate price level will (through $\theta$ ) also depend upon the variances of the market specific demand and supply shocks. These variances are unobservable and are modeled here as part of the additive error term in our final estimating equation.

${ }^{10}$ This specification does not rule out the possibility that $\bar{\sigma}_{\Delta p}^{2}$ is zero. Rather it allows for the possibility that in some long-run, "natural rate," sense there is always some variability in the inflation rate.

${ }^{11}$ In Friedman's analysis changes in the variability of inflation, and therefore of aggregate demand or supply, would affect output whether these changes were perceived or not. Therefore, whether our proxies for the moving variances contain information not available to market participants would not appear to matter. The role of changes in aggregate demand and supply variability within the Lucas model does, however, depend on whether the changes in variability are perceived by market participants. Since we plan to use these same proxies to measure the effects of continuous changes in demand and supply variability on the terms of the output-inflation tradeoff within the modified Lucas model of cyclical fluctuations in income, we construct the proxies using only information available to market participants.

12 Nelson (1979) (1981) provides evidence for the U.S. that the residuals from a deterministic trend representation of real output are nonstationary and therefore do not measure the cyclical proportion of real output. Nelson suggests that, rather than a fixed trend for natural output, there is instead a negative relationship between the natural rate of output and the level of inflation, along lines suggested by Friedman. Our specification of detrended real output would appear to be consistent with this view. 13 This follows from footnote 9 , the fact that $\theta$ is a decreasing function of $\sigma_{x}^{2}$
and $\sigma_{\mu}^{2}$, and is demonstrated in the appendix cited in footnote 4 .

${ }^{14} \mathrm{~A}$ caveat should be borne $i$ mind. Since the theoretical relationships between the coefficients on $\Delta x_{t}$ and $\mu_{t}$ and $\hat{\sigma}_{\Delta p, t}^{2}$ are nonlinear, and since these coefficients also depend upon $\sigma_{w}^{2}$ and $\sigma_{\eta}^{2}$, our specification of these coefficients given by (7) is only an approximation. (The nature of the nonlinearity is shown in the appendix cited in footnote 3.)

15 Given the behavior of the energy price shock specified by (9), now the lagged value of the energy price conveys information about the current energy price level. Hence equation ( $4^{\prime}$ ) is not simply derived by substituting (9) into (4), but requires a modification of the way price expectations are formed taking account of this information. 
16 The quarterly data used are: for real output $y_{t}$, real gross domestic product; for nominal income $x_{t}$, nominal eross domestic product. These series along with the series for the import price are from International Financial Statistics, International Monetary Fund; except for the most recent observation the data was taken from the. IMF computer tape. The energy price series is the index "Basic Materials and Fuel Used in Manufacturing Industry" from the Monthly Digest of Statistics, Central Statistical Office, London, various issues.

17

If it is assumed that inflation variability is constant over time, so that $\delta_{\Delta p, t}^{2}=\bar{\sigma}_{\Delta p}^{2}$, then $\beta_{0}\left(=-\beta_{1} \sigma_{\Delta p}^{2}\right)$ cancels $\beta_{1} \theta_{\Delta p, t}^{2}$ in $(6)$ and there can

be no type 3 effect. Also there can be no type 1 or type 2 effect due to changes in the coefficients on $\Delta x_{t}$ or $\mu_{t}$ caused by changing inflation variability. However, there can be a type 2 effect caused by the direct effect of the supply shock $\mu_{t}$. Estimates of (6) under the constant inflation variability assumption indicated that the coefficients on $\Delta x_{t}, \mu_{t}$, and $y_{t-1}$ were all significant with the expected sign, whether $\mu_{t}$ was measured $f^{\prime}$ the energy price shock or the import price shock.

18 Bearing this caveat in mind, for either measure of the supply shock $\mu_{1}$, the estimated coefficients on $\Delta x$ had the expected sign and were significant, while those on $\mu_{t}$ were not. For the energy price measure of the supply shock, the estimates suggested that the type $3 \mathrm{effect}$ is due to the changing variability

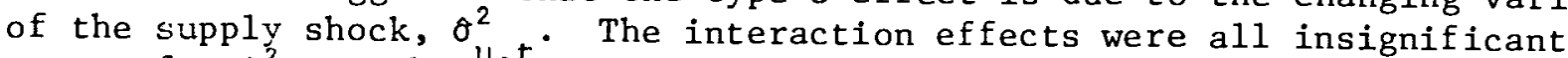
except for $\partial^{2}{ }^{\mu}$ which,however had the wrong sign. For the import price measure of the supply shock, the estimates suggested that the type 3 effect is due to the changing variability of both aggregate demand and supply, $\hat{\sigma}_{x, t}^{2}$ and $\hat{\sigma}_{\mu, t}^{2} r e-$
spectively. The one significant interaction effect was for $\sigma^{2}, \mu_{t}$, suggesting that the type 2 effect operating via the changing cófficient on $\mu$, indicated in line 4 of Table 1 , is due to changing aggregate demand variabiliEy.

${ }^{19}$ The increase is approximately 40 percent. Note that the average value of the moving variance proxy for a subperiod is not the same thing as the variance of the inflation rate calculated over the whole subperiod. We focus on the moving variance proxy $\hat{\sigma}_{\Delta p, t}^{2}$ because it is the measure used in the regressions reported in Table 1.

${ }^{20}$ Note that this calculation takes into account the adjustment lag implied by the estimated coefficient on the lagged dependent variable $y_{t-1}$. These calculations make use of the fact that the difference in the log of a variable is approximately equal to the percent change in the variable.

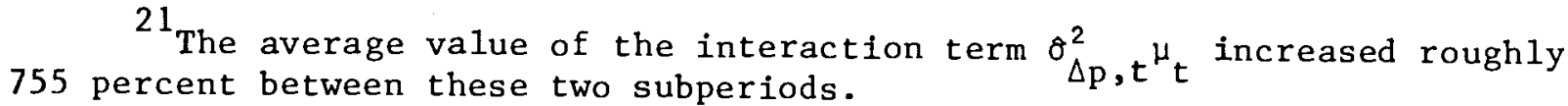

${ }^{22}$ The comment in footnote 20 applies here as well. 
REFERENCES

Alberro, Jose, "The Lucas Hypothesis on the Phillips Curve: Further International Evidence," Journal of Monetary Economics, 7 (March 1981), 239-251.

Azariadis, Costas, "A Reexamination of Natural Rate Theory," American Economic Review, 71 (December 1981), 946-60.

Blizder, Alan S., "Monetary Accomodations of Supply Shocks Under Rational Expectations," Journal of Money, Credit and Banking, 13 (November 1981), 425-38.

Cukierman, Alex and Wachtel, Paul, "Differential Inflationary Expectations and the Variability of the Rate of Inflation," American Economic Review, 69 (September 1979), 595-610.

Durbin, J., "Testing for Serial Correlation in Least-Squares Regression When Some of the Regressors Are Lagged Dependent Variables," Econometrica, 38 (May 1970), 410-422.

Evans, Paul, "Monetary Uncertainty and Employment," unpublished manuscript, Stanford University, 1978.

Friedman, Milton, "Inflation and Unemployment," Journal of Political Economy, 85 (June 1977), 451-72.

Froyen, Richard and Waud, Roger, "Further International Evidence on OutputInflation Tradeoffs," American Economic Review, 70 (June 1980), 409-21.

Keynes, John M., Tract on Monetary Reform. New York: Harcourt Brace and Company, 1924.

Levi, Maurice D. and Makin, John M., "Inflation Uncertainty and the Phillips Curve: Some Empirical Evidence," American Economic Review, 70 (December $1980), 1022-27$.

Lucas, Robert E. Jr., "Expectations and the Neutrality of Money," Journal of Economic Theory, 4 (April 1972), 103-24.

, "Some International Evidence on Output-Inflation Tradeoffs," American Economic Review, 63 (June 1973), 326-34.

, "An Equilibrium Model of the Business Cycle," Journal of Political Economy, 83 (December 1975), 1113-44.

Mullineaux, Donald J., "Unemployment, Industrial Production and Inflation Uncertainty in the United States," Review of Economics and Statistics, 62 (May 1980), 163-69. 
Nelson, Charles R., "Recursive Structure in U.S. Income, Prices, and Output," Journal of Political Economy, 87 (December 1979), 1307-27.

, "Adjustment Lags Versus Information Lags," Journal of Money, Credit and Banking, 13 (February 1981), 1-11.

Okun, Arthur, Prices and Quantities. Washington: The Brookings Institution, 1981.

Ramsey, James B., "Tests for Specification Errors in Classical Linear Least Squares Regression Analysis," Journal of the Roya1 Statistical Society, Ser. B, 31 (1969), 350-71.

Sargent, Thomas, "The Persistence of Aggregate Employment and the Neutrality of Money," unpublished manuscript, University of Minnesota, 1977.

Thursby, J.G. and Schmidt, P., "Some Properties of Tests for Specification Error in a Linear Regression Mode1," Journal of the American Statistical Association, 72 (1977), 635-641. 